\title{
Seeing Causing
}

DOI:

10.1111/j.0066-7372.2003.00072.x

\section{Document Version}

Accepted author manuscript

Link to publication record in Manchester Research Explorer

\section{Citation for published version (APA):}

Beebee, H. (2003). Seeing Causing. Proceedings of the Aristotelian Society, 103, 257-280.

https://doi.org/10.1111/j.0066-7372.2003.00072.x

\section{Published in:}

Proceedings of the Aristotelian Society

\section{Citing this paper}

Please note that where the full-text provided on Manchester Research Explorer is the Author Accepted Manuscript or Proof version this may differ from the final Published version. If citing, it is advised that you check and use the publisher's definitive version.

\section{General rights}

Copyright and moral rights for the publications made accessible in the Research Explorer are retained by the authors and/or other copyright owners and it is a condition of accessing publications that users recognise and abide by the legal requirements associated with these rights.

\section{Takedown policy}

If you believe that this document breaches copyright please refer to the University of Manchester's Takedown Procedures [http://man.ac.uk/04Y6Bo] or contact uml.scholarlycommunications@manchester.ac.uk providing relevant details, so we can investigate your claim.

\section{OPEN ACCESS}




\title{
SEEING CAUSING
}

\author{
Helen Beebee
}

\author{
Please do not cite this version. The published version is: \\ 'Seeing Causing', Proceedings of the Aristotelian Society 103 (2003), 257-80
}

\section{I}

Introduction. Imagine that you are watching the final stages of a game of pool. One of the players lines up her shot and hits the white ball with the cue. You watch the white ball move towards the black and make contact with it, whereupon the black moves towards the pocket. How does your visual experience represent the scene that is being played out before your eyes?

When asked to describe their experience, normal observers, with no philosophical axe to grind, will typically (though not invariably) invoke causal concepts. They will say that they saw the white ball hit the black, push it, move it, make it go, propel it across the table, or some such. Someone who knows something about the philosophy of causation, on the other hand, is likely to give an answer that (apparently) reflects their metaphysical commitments. Typically, someone who thinks causation is an intrinsic relation - a relation whose obtaining is solely a matter of what is going on on the table - will agree with normal observers, and report that they saw the white ball cause the black to move. ${ }^{1}$ Typically, those who think that causation is an extrinsic relation, whose obtaining depends on what goes on at other places and times, give a much more guarded answer. What they saw, they will say, is the white ball moving until it was touching the black, at which point the black began to move. However, they will add that, since they know or believe that such sequences of events are, in fact, causal (since they are constantly conjoined or instantiate laws, say), they inferred, on the basis of their experience together with background beliefs, that the white ball caused the black to move.

For the sake of brevity, I shall call someone who thinks that causation is an intrinsic relation a 'singularist', and someone who thinks that it is an extrinsic relation, whose obtaining depends somehow or other on facts about patterns of regular association between events or states of affairs, a 'regularity theorist'. ${ }^{2}$ The aim of this paper is to show that regularity theorists need not be so reticent in describing their experience, for they can accept that their experiences can (and routinely do) represent what is going on before their eyes in causal terms without thereby undermining their avowed metaphysical views. The point of

1. Examples of philosophers who hold that causal relations are (a) intrinsic and (b) capable of being experienced include Anscombe (1993), Armstrong (1993, 1997), Cartwright (2000), Ducasse (1967a, 1967b, 1993), Fales (1990), and Menzies (1998).

2. For some statements of singularism see Ehring 1997: 7 and Menzies 1998: 339. Singularism, so conceived, need not deny that there is a connection - conceptual or otherwise - between causation and regularity (although some do; see Anscombe 1993). But, insofar as a singularist thinks that there $i$ such a connection, it will be the causal relation that grounds or explains the regularity, and not the other way around (see for example Strawson 1987 and Heathcote and Armstrong 1991). Those offering counterfactual analyses of causation count as regularity theorists in my sense, so long as they also accept Lewis's analyses of counterfactuals and laws. 
showing this is to pre-empt an objection to regularity theories which runs as follows: Our experience manifestly does sometimes represent what is going on before our eyes in causal terms. But, since a regularity theorist cannot hold that our experience is capable of so representing things, no regularity theory of causation can be correct. And, of course, if I am right, that objection is no good, since its second premise is false. ${ }^{3}$

There may, of course, be independent reasons to deny that our experience can represent what is going on before our eyes in causal terms; or there may be no particular independent reason to think that our experience does sometimes so represent it. If so, the regularity theorist can happily accept that conclusion too, since the argument I am attempting to preempt fails anyway. In presupposing, in most of what follows, that our experience can so represent our environment, I do not mean to commit myself to that view; I simply want to show that it is a view that a regularity theorist is not barred from holding just in virtue of her sparse metaphysical commitments.

\section{II}

1. A Simple Argument. Imagine you are looking at the pool table again. Let us call thin an experience of a causal sequence whose representational content consists solely in the movement of the balls. A thin experience might be reported by something like, 'I saw the white ball move across the table until it was adjacent to the black ball, whereupon the black began to move in the direction of the pocket': it represents the sequence's kinematic features but not its causal features. And let us call thick an experience (or belief) whose representational content has a causal element ('the white ball propelled the black towards the pocket', 'the contact of the white made the black move', and so on).

The claim I want to argue against is the claim that regularity theorists are committed to the view that thick causal experience is impossible. In this section, I refute a very simple argument for that claim, and also argue that there are no empirical results in the psychology of perception that might bar a regularity theorist in particular from holding that thick experience is possible.

The simple argument (S) goes like this:

If a regularity theory is true, cases of causation are no more than instantiations of regularities.

Therefore

Causal relations must be inferred from current, thin experience together with beliefs about past, similar regularities.

\section{Therefore}

\footnotetext{
3. I have heard the objection in conversation many times, although singularists have, so far as I can tell, resisted putting it in print. David Armstrong comes quite close (1997: 213-4); so does Nancy Cartwright. 'For the Humean', she says, 'a singular causal claim cannot be established directly; we first need a general claim, based on a regular association' (2000: 47); and she goes on to give examples of scientific experiments where singular causation can be 'established directly'. The argument bears some affinity to the argument I am concerned with here; and of course the main aim of this paper is to refute the claim that a Humean is required to say that singular causal claims cannot be 'established directly'. However her argument explicitly concerns what can be established on the basis of 'one-shot experiments' in science, and not whether or not ordinary experience can have a causal content. Still, if I am right, Cartwright's objection to regularity theories is met. She says, 'empiricists have tended to believe that there are no reliable methods for testing singular causal claims directly. But this is a mistake' (2000: 57). I agree.
} 
Thick causal experiences are impossible.

If an observer reports that the white ball caused the black to move (say), then, strictly speaking - so the argument goes - she must, if a regularity theory is true, be doing more than merely reporting on the content of her experience; rather, the bearer of thick content is a belief which is the result of an inference from her (thin) experience together with a belief to the effect that past movements like the movement of the white have regularly been followed by movements like the movement of the black.

(S) is, I shall argue, flawed on two counts. First, there are two possible readings of 'infer'. On one reading, it is true (granted (S1)) that causal relations are inferred, but this does not entail (S3). On the other reading, there is no obvious reason to suppose that causal relations are inferred, so there is no obvious reason to believe (S2). So either way (unless there are non-obvious reasons to believe (S2) - an issue I address in section III) the argument fails. Second, given that inference from background theory or collateral beliefs or some such is needed for thick experience, the regularity theorist need not be committed to thinking that such collateral beliefs take the form of beliefs about regularities.

First, then, there is the claim that the regularity theorist is committed to holding that thick experiences are impossible: one must rather infer the obtaining of causation on the basis of one's thin experience. I take the basic thought here to be that since, according to a regularity theory, there is no intrinsic causal relation present in the scene before one's eyes, the obtaining of the (extrinsic) causal relation can form no part of the visual stimulus on the basis of which one comes to make a thick observational report. Hence any such report must be inferred. However, pretty much everyone these days - or at least everyone whose views are going to be relevant to the issue at hand - agrees that experience can be (and often is) theoryladen, or is generally a partly cognitive process. On a broad reading of 'infer', to say that something is inferred is to say no more than this. ${ }^{4}$ On that reading, to say that something is inferred is not to rule out the possibility of its being the content of an experience. Visual stimuli in general massively underdetermine the representational content of one's experiences (Fodor 1983). If this were not so, our experience could not represent the external world as having any interesting features at all. In particular, even the thin experience which represents the situation on the table as being one in which the balls are in motion goes well beyond one's visual stimuli. That experience represents the scene as containing two solid, spherical objects, whereas the same visual stimuli could be produced by hollowed-out hemispheres. ${ }^{5}$ The mere fact that thick causal experience would, according to a regularity theorist, require some sort of background theory (and thus 'inference' from that theory) in order to have the content it has is thus no bar to its possibility.

Is there a reading of 'infer' according to which something's being inferred does rule out the possibility of its being the content of experience? One such reading might, in principle, come from psychological, rather than philosophical, considerations, and I briefly address those considerations below. At this stage I want to argue that there is no phenomenologically obvious reason (none that I can think of anyway) why regularity-theory causation must be inferred, in the current restrictive sense, rather than experienced.

I can think of only one prima facie phenomenological reason to hold that causation must be inferred, and it runs as follows. There is no 'way it looks' for a sequence to be an instance of a regularity; hence, given a regularity theory of causation, there can be no way it looks for

4. This seems to be Armstrong's sense of 'inferred' in the argument referred to in note 3 above.

5. Anscombe makes a similar point in the context of arguing against Hume's claim that causation cannot be perceived (1993: 92). 
a sequence to be causal; hence experiences cannot have thick content. The response runs as follows. The regularity theorist can accept that there is no way it looks for a sequence to be an instance of a regularity. The issue we are concerned with is whether thick content is the content of perceptual experience, or whether it is the content of a belief inferred from the (thin) content of one's experience together with background beliefs. Whether there is something it looks like to be an instance of a regularity is irrelevant to that issue. What is relevant is whether or not there is something it looks like to be the kind of sequence that one antecedently has certain beliefs about, or has experienced on previous occasions, or whatever. But of course the regularity theorist who believes in the possibility of thick experiences will claim, precisely, that there is something such sequences can look like - since that is precisely what is captured by thick experiences.

If this does not sound convincing, consider an analogous case. Suppose that, as you are leaving the room, Jane shouts, 'Shut the door!'. How would you report your auditory experience? One way to do it is to say, 'Jane told me to shut the door'. Semantic properties of utterances are, of course, highly extrinsic. There is nothing in the sequence of sounds coming from Jane's mouth that determines, just by itself, that they constitute the command that you shut the door. There is, in other words, no way it sounds, independently of the hearer's linguistic knowledge, for a sequence of sounds to be a command to shut the door. By analogy with the causal case, we could distinguish between an experience with 'semantically thin' content - an experience that represents Jane as producing a sequence of sounds - and an experience with semantically thick content, which represents Jane as telling you to shut the door. Does the extrinsicality of semantic properties - and thus the fact that there is no way it sounds for a sequence of sounds to be a command to shut the door - give us any phenomenological grounds for holding that thick semantic experiences are impossible? No. If phenomenology is to settle anything here, it certainly does not support that claim. So long as both you and Jane are competent English speakers, it seems that your auditory experience represents Jane as having told you to shut the door. ${ }^{6}$

There do not seem to be any obvious philosophical reasons, then, why we should accept (S). On a broad interpretation of 'infer', (S2) is true but does not, together with (S1), entail (S3). On a narrower interpretation of 'infer', according to which (S3) does follow, we have yet to find any grounds for believing that (S2) is true. There might, of course, be further philosophical reasons to believe (S2), and I return to that issue in section III.

What about the second flaw in the argument, which, I said, is that claim that the regularity theorist must hold that the background theory in question must take the form of a belief to the effect that like events have been followed by like in the past? Well, I see no reason to believe it. According to Hume, of course, the 'impression of necessary connexion' only comes about once one has experienced similar sequences in the past; but we don't need to take Hume's word for it. Moreover, beliefs with causal content need not be inferred from background beliefs about regularities (one can acquire causal beliefs in all kinds of ways: testimony or superstition, for example). I see no philosophical reason to think that experiences with causal content should be any different.

2. The Psychology of Causal Perception. I said above that there are no obvious philosophical reasons to hold that causal relations are inferred, in a sense of 'inferred' that thereby rules out

6. Fodor (1983: 36-9) makes a similar point with respect to grammatical features of utterances: 'Patently, [being a noun] has no sensory/acoustic correspondent; there's nothing that nouns qua nouns sound like' (1983: 37). But, he argues, that is no bar to counting grammatical properties as observable. 
the possibility of thick experiences. But I did not attempt to say anything about what such a sense of 'infer' might amount to. For the rest of this section I discuss (very briefly) the psychology of what psychologists sometimes call 'perceptual causality'. There are two reasons for doing so. First, there is, prima facie, a psychological way to give a sense of 'infer' which distinguishes between thick experiences on the one hand and thick beliefs inferred from thin experiences on the other, and it is worth seeing whether there is psychological evidence that causation falls into one category or the other. The results, I shall claim, are rather mixed, but certainly leave open the possibility that thick experiences, in the relevant sense, are possible. And second, suppose that psychological evidence points to the possibility of genuine causal experience. Then there is a question about whether the nature of the psychological processes involved in causal experience turn out to involve background theory or learning history in a way that should cause concern for a regularity theorist. I argue that there is no such cause for concern.

In his The Perception of Causality (1963), first published in 1946, Albert Michotte sets out to refute experimentally Hume's claim that 'in perceptual experience we have no direct impression of the influence exerted by one physical event on another' (1963: 6). The most basic kind of experiment he uses involves coloured squares moving in a way roughly similar to the way billiard balls move. The subject sits in front of a screen and watches as a small black square (object $A$ ) moves horizontally from left to right towards a red square (object $B$ ). Object $A$ stops immediately on contact with object $B$, which then moves off, at the same or lower speed, to the right. The subject is then asked to report what she sees. Michotte reports that the result of this basic experiment 'is perfectly clear; the observers see object $A$ bump into object $B$, and send it off (or 'launch' it), shove it forward, set it in motion, give it a push. The impression is clear; it is the blow given by $A$ which makes $B$ go, which produces $B$ 's movement' (1963: 20).

One way in which Michotte's results have been interpreted runs as follows. Suppose that perception is modular. That is, roughly: suppose that perceptual processes are not comprehensively penetrated by all the perceiver's background information. (For example, the verdict delivered by our perceptual system when confronted by the Mueller-Lyer illusion is that the lines are different lengths, even when we know that they are in fact the same length. The information that they are the same length is thus not information that is accessible to our perceptual system (Fodor 1983: 32-4).) The modularity hypothesis seems to give us a test for what is and is not delivered by our experience. Is an observational report that $p$ sensitive to all one's background information or not? If so, then the report cannot be delivered by the perceptual system alone, since that system is not comprehensively penetrated by all our background information. On the other hand, if the report is not sensitive to all one's background information, that provides evidence that the report is delivered by the perceptual system, and is not inferred from what is delivered by perception together with background information.

Michotte's results have been interpreted by some psychologists as providing evidence that subjects' observational reports as of $A$ 's causing $B$, pushing it off, making it go, or whatever, are indeed delivered by the perceptual system, since such reports are unaffected by the fact that the subjects know what they were looking at to be mere coloured patches in motion, not objects, one of whose motion was causing the other's. ${ }^{7}$ As Brian Scholl and

7. Whether or not Michotte-type experiments reveal a genuine causal illusion (analogous to the Mueller-Lyer illusion) is, in fact, debatable. It is plausible to think that subjects automatically take the movements of the lights to be representations of real-world collisions, and make their observational reports on that basis; in which case it is not obvious that there is an illusion of causation at all. (When one reports, on watching The Poseidon Adventure, that Gene Hackman has fallen into a pit of boiling water, one is not obviously suffering from an 
Patrice Tremoulet say, the 'phenomena of perceptual causality' are 'mandatory in the way that most visual illusions are: to the degree that the events are clearly perceived ..., the causal ... nature of the resulting percepts is nearly irresistible. This reflects a type of encapsulation: despite the fact that observers know that the displays are not really causal ..., this knowledge does not appear to be taken into account by the mechanisms that construct the percepts' (2000: 306).

Michotte's main conclusion, that we do have thick experiences, is accepted by most (though not all) contemporary psychologists, although there is some scepticism about the claim that perceptual causality is modular (Schlottmann 2000). However, a common theme of some recent work on perception of and reasoning about objects, causation and animacy is that the boundary between perception and reasoning is not as clear-cut as has traditionally been supposed. Elizabeth Spelke and Gretchen Van de Valle, commenting on the way that infants' perception of and reasoning about objects is sensitive to certain physical principles, say: 'The processes that underlie perceiving and reasoning about objects ... appear to lie at the border of what is traditionally considered 'perception' and what is traditionally considered 'thought' (1993: 155). Scholl and Tremoulet say that 'one of the reasons that [the phenomena of 'perceptual causality and animacy'] are interesting is that they both have the character of visual percepts yet involve what are traditionally thought to be higher-level concepts' (2000: 305). Anne Schlottmann agrees that 'perceptual causality is interesting because it lies at the interface of perception and cognition' (2000: 442).

It may turn out, then, that the traditional question of whether causation is perceived or inferred is one that does not admit of a clear answer. If so, then, of course, the regularity theorist will be perfectly happy to accept that result. My overall aim in this paper is only to show that a regularity theory of causation is consistent with the claim that thick causal experiences are possible.

What about the second reason I gave for paying attention to psychological results, namely the worry that the kind of background theory or learning history that affects causal experience might turn out to cause concern for a regularity theorist? First, there is some evidence that short-term associative learning does not affect causal experience (Schlottmann and Shanks 1992), and this might, prima facie, be thought to raise a worry for the regularity theorist. It doesn't. For one thing, the regularity theorist is not at all committed to thinking that shortterm associative learning should make a difference. (As Schlottmann says, 'one hour of laboratory practice lacks the force of lifelong experience' (2000: 441).) Moreover, as I already said in the discussion of argument (S) above, the regularity theorist is not committed to thinking that even long-term associative learning of predictive relationships is the only, or even the primary, factor influencing causal experience. It might be, for example, that the primary factor is a general theory about what kinds of phenomena typically cause what, or some fragment of such a theory (e.g. the part of the theory that concerns kinematic sequences).

Second, there is some evidence to suggest that infants as young as six months can 'perceive causation' in a simple kinematic sequence (Leslie and Keeble 1987). ${ }^{8}$ One prima

illusion, even though one knows that he has not in fact done so.) I am inclined to think (though of course this is mere armchair speculation) that observers would make similar reports to those elicited by Michotte if they were confronted with real kinematic sequences - a pool shot, say - in the case where they knew that the balls were controlled independently (by magnets, say). That looks more like a genuine case of illusion.

8. 'Perceive causation' is in scare quotes because the claim should not be taken to be the claim that six-montholds have thick experience in the sense that they represent kinematic sequences as being causal - since they lack anything like the full-blown concept of causation that would make such representation possible. What six- 
facie worry that this might raise runs as follows: six-month-old infants are not in a position to theorise about anything and have not had very much time for associative learning. So they must be responding to a simple, straightforwardly observable, intrinsic relation between events (or an illusion thereof) rather than bringing background knowledge or associative learning to bear on the scene before their eyes.

This worry is also ill-founded, because nothing in a regularity theory rules out the possibility that humans have an innate capacity to process visual stimuli in certain principled ways rather than others. There is evidence, for example, that very young infants' perception of objects accords with some basic physical principles: a 'principle of contact' (surfaces move together iff they are in contact) and a 'principle of cohesion' (surfaces lie on a single object iff they are connected) (Spelke and Van de Valle 1993: 137). Nothing in a regularity theory of causation rules out the possibility that infants' causal perception likewise accords with basic causal principles - principles that need not be a result of associative learning and need not form part of a sophisticated, learned 'background theory' (in a narrow sense of 'theory') about the causal structure of the world.

There are interesting psychological questions to be answered, then, concerning precisely which background beliefs or theories or kinds of associative learning affect our experience of causation, whether the perceptual processing is learned or innate or a combination of the two, and so on. But, of course, such questions are best left to psychologists. My basic point here is simply that I cannot see how a regularity theory might turn out to be inconsistent with any answers that psychologists might come up with.

\section{III}

1. A Worry about Perceptual Knowledge. I argued in section II that the fact that background theory is needed for observational reports of causation is no grounds for denying that they are genuine reports of thick experiences. The psychological evidence suggests that such observational reports are indeed reports of thick experiences aided by, but not inferred (in the sense of 'inferred' that is incompatible with their being genuine reports of experiences) from background theory.

There is, however, a further worry about combining a regularity theory of causation with the view that thick causal experiences are possible, to which the rest of this paper will be devoted. Grant the point just described, and also grant the point made in section II that the background theory in question need not take the form of beliefs about past regular association. But now suppose that, in general, if one's experience delivers the verdict that $p$, then - if certain further constraints are met (including, of course, $p$ 's being true) - one thereby non-inferentially knows that $p$. Call this the 'Perceptual Knowledge Principle', (PKP). By 'experience delivers the verdict that $p$ ', I mean that (a) one's experience represents $p$ as being the case, and (b) one thereby, non-inferentially, comes to believe that $p$. This seems like a plausible general principle, given a satisfactory way of filling the 'further constraints' clause. Constraints in the case of perceptual knowledge are typically taken to be externalist no-funny-business constraints designed to rule out perceptual knowledge in cases where one's experience is veridical but might easily not have been (being in an environment with fake barns, mules disguised as zebras, and so on), together with a reliability constraint: the mechanisms that deliver the verdict that $p$ must be working properly.

month-olds do appear to be able to do is respond differently to Michotte-type kinematic sequences that would ordinarily elicit thick causal reports from adult observers, compared to kinematic sequences that would not elicit such reports. 
Now here's the worry. Suppose that I have a veridical experience that represents the white ball as causing the black to move, and that I thereby come, non-inferentially, to believe (truly) that the white ball has just caused the black to move. Suppose also that there is no funny business going on - there are no hidden magnets or remote control - and that I am functioning fine. Then according to (PKP) I do thereby know, non-inferentially, just on the basis of my visual experience, that the white ball caused the black to move. But now suppose also that a regularity theory of causation is correct, and that I know this to be so. So I know that in order for it to be the case that the white ball caused the black to move, that sequence of events must instantiate a regularity. I can now infer, just on the basis of my visual experience and some philosophical reflection, that other movements of billiard balls (similar to the movement of the white ball I just witnessed), in far-off places and times, are regularly followed by movements similar to the movement of the black that I just witnessed. So - since I have performed a straightforward inference from known premises - it seems as though I thereby know that such a regularity obtains.

The worry is that what I thereby get to know is rather too impressive, given its basis just on a single visual experience together with some philosophising. For surely a single experience together with some $a$ priori theorising cannot yield knowledge about what happens in far-off places and times. As if solving the problem of induction could be that easy!

What I thereby come to know is not, of course, of the form ' $F$ s are regularly associated with $G$ s', since I do not thereby know which regularity is being instantiated. All I (allegedly) come to know is that there are properties $F$ and $G$, instantiated by the first and second event (i.e., cause and effect) respectively, such that $F$ s are regularly associated with $G$ s. Even granted this caveat, however, the worry remains. To know that some regularity or other is being instantiated is to know something about the uniformity or continued orderliness of nature, since it is to know that the future will resemble the past in some (non-trivial) respect or other.

The conclusion we ought to draw - so the imagined objector says - is that if a regularity theory of causation is correct (and we could in principle know this to be so), we cannot after all have non-inferential perceptual knowledge about causation. But, since the other conditions required for perceptual knowledge appear to be met (reliability plus no funny business), the only way to deny that we can have non-inferential perceptual knowledge of causation is to deny that our experience is capable of delivering causal verdicts. For if we do deny the latter, knowledge of causation will turn out to be inferential after all. In particular, knowledge that $A$ caused $B$ will require inference from the belief to the effect that $A$-type events are regularly associated with $B$-type events, thus blocking the induction-justifying argument by rendering it blatantly circular.

I shall address this argument for the impossibility of thick experiences by first showing that some standard conditions for perceptual knowledge are, in fact, met in the case of causation. I then consider two broad ways of countering the argument. The first agrees that we cannot have perceptual knowledge of causation, but claims that there are further conditions for perceptual knowledge that are not met. This move thus accepts that thick experiences are possible but denies that such experiences can ever generate non-inferential perceptual knowledge of causation. The second accepts that the other conditions can be met, so that perceptual knowledge of causation is possible, but denies that this leads us to an implausibly quick-and-easy solution to the problem of induction. Both strategies thus accept (PKP) but deny that combining it with a regularity theory of causation leads to trouble. 
2. Are the Conditions for Perceptual Knowledge Met? My first task in this section is to show that some standard externalist requirements for perceptual knowledge - reliability, truthtracking, and no relevant alternatives - can be met in the causal case. I do this by showing that they are, in fact, met in the standard case where one sees the white ball cause the black ball to move. My second task is to show that, even if one grants that externalist requirements are met, there may be other requirements which cannot be met. If this is so, then the allegedly unwelcome epistemic consequence of the possibility of thick causal experience - that it provides a basis for inductive knowledge - is not a consequence at all.

One standard condition for perceptual knowledge that $p$ is that the mechanisms responsible for delivering the verdict that $p$ are reliable. This condition is met, I claim, in the case of causation. Generally speaking, given what we take ourselves to know about the causal structure of the world, experience tends to deliver the verdict that $X$ caused $Y$ just when $X$ does in fact cause $Y$. There are, of course, exceptions. Sometimes, when the causal mechanism in virtue of which $X$ causes $Y$ is hidden from view, or works in a way we are unfamiliar with, experience does not deliver the verdict that $X$ causes $Y$ even though $X$ does in fact cause $Y$. When I press the 'on' button on my computer, a light goes on. I don't think I see that sequence as causal, even though I know that it is. Conversely, sometimes one's experience represents a sequence of events as causal it is not, which goes some way towards explaining the enduring popularity of magic shows. (When the magician taps his wand and says the magic word, the rabbit disappears. That, I think, looks causal - to small children anyway. Maybe one's experience stops representing the sequence as causal once one knows enough about the world to know that it could not possibly be causal.) But of course there is nothing distinctive about the causal case here; experience sometimes delivers the wrong verdict about whether something is red or round or close by or a tomato.

It is, of course, just possible that we are routinely massively in error in our non-inferential perceptual beliefs about causation. Movements just like the movement of the white I am currently observing might, conceivably, not be regularly associated with movements like that of the black after all. Any regularity theorist who takes this to be a serious epistemic possibility will presumably doubt whether the mechanisms responsible for delivering the verdict that there is causation going on in front of them are reliable. But, again, the same applies in the non-causal case: someone who seriously thought that for all he knew, the malicious demon could be doing her evil work would not take his perceptual mechanisms to be reliable.

A second standard condition for perceptual knowledge that $p$ is a Nozick-style truthtracking clause to the effect that, had $p$ not obtained, one's experience would not have delivered the verdict that $p$ (Nozick 1988). This condition also seems to be met in the causal case. Suppose we require for perceptual knowledge that $p$ that in close possible worlds where $p$ is false, one's experience does not represent the environment as being such that $p$ is true. Thus the barn-perceiver who is unlucky enough to be in fake-barn country cannot perceptually know that there is a barn in front of her, since there are close possible worlds where there is no barn (but a fake one) in front of her and yet her experience still delivers the verdict that there is a barn in front of her. But, in the ordinary case (where there are no fake barns in the vicinity), she does know, just by looking, that there is a barn there, since close possible worlds in which there is no barn present will be worlds where her experience does not deliver the verdict that there is a barn there (since worlds where there is instead a fake barn in front of her will not be close worlds). Similarly, I think, for causation. In the ordinary case, where there is no funny business going on, close possible worlds where the white ball does not cause the black ball to move will not be ones in which there $i s$ funny business going on; rather, they will be perfectly ordinary worlds where you miss the white all together, or 
you hit it in the wrong direction, or without enough force to get it all the way to the black. In such worlds my experience will not deliver the verdict that the white caused the black to move.

A third possible condition that seems to be met is a Goldman-style relevant-alternatives clause (Goldman 1976). Goldman claims that in order to non-inferentially perceptually know that $p$, there must be no perceptually indistinguishable relevant alternatives to $p$. Again, this discounts the barn-observer in fake-barn country from perceptually knowing that there is a barn in front of her, since the possibility that what she is looking at is a fake barn is a relevant alternative. But in the ordinary case, this possibility is not a relevant alternative, so the barnobserver does know that there is a barn in front of her. Again, in ordinary circumstances, there are no perceptually indistinguishable relevant alternatives in the causal case either. The perceptually indistinguishable possibility that there are magnets under the table, or that the balls are being moved by remote control, is not a relevant alternative.

One might be tempted by the thought that, in the causal case, given a regularity theory of causation, the following is a relevant alternative: the kinematic features of the situation are exactly the same but there is no causation - not because of hidden mechanisms or other funny business, but because there is no regularity instantiated by the observed events. (Similarly, one might be tempted by the thought that possible worlds where that situation obtains are close by, and hence that thick experiences violate the truth-tracking requirement.) But why should we think this? The mere fact that the alternative in question is perceptually indistinguishable from the actual scene does not, of course, automatically make it a relevant alternative - we need additional reasons, besides indistinguishability, to think that the alternative is relevant. Those with leanings towards inductive scepticism might take themselves to have such reasons: they take the possibility that there is no regularity to be a live option in just the way that an external world sceptic takes the possibility of deception by a malicious demon to be a live option. An inductive sceptic will doubtless hold that the norelevant-alternatives requirement is not satisfied, and hence will not take herself to know that the white ball caused the black to move. But, given an externalist understanding of the norelevant-alternatives clause, it does not follow that she does not know; nor does it follow that the non-sceptic does not know.

Standard externalist conditions for perceptual knowledge seem, then, to be met in the case of causation. But there might be further constraints on perceptual knowledge that render thick experience incapable of generating non-inferential causal knowledge. This view has been argued for by Christopher Peacocke. On Peacocke's view, externalist conditions provide necessary but not sufficient conditions for a true belief to be knowledge. In addition, the belief must be 'rationally held', and what makes this so is (roughly) that the method by which the belief is acquired is appropriate to the 'canonical acceptance conditions' for the content of the belief (1986: Chapters 9 and 10). Peacocke argues that in the case of non-inferential beliefs based on thick experience (experience that represents one's environment as causal), the rationality requirement is not met. He does so because he holds that 'the canonical acceptance conditions for the holding of a causal relation ... have to do ultimately with laws, however analyzed, and in any particular case - and perhaps in general - impressions of causation are only a posteriori associated with the relation of causation in the world, whatever it consists in' $(1986: 157)^{9}$. The general idea here is that if the canonical acceptance conditions concern laws (or regularities), and knowledge requires appropriateness of method

9. Peacocke is not here committing himself to a regularity theory of causation (one might, after all, hold that the obtaining of a law requires more than mere regularity). So the reasons offered would count equally against the possibility of perceptual knowledge of causation given a non-regularity law-based account of causation. 
to canonical acceptance conditions, then a single thick experience will not be a method for acquiring a causal belief that is appropriate to those conditions. Rather, one would need to establish independently that one's thick experience is in fact a reliable indicator of causation, in which case the resulting knowledge of the obtaining of a causal relation would not be noninferential perceptual knowledge.

Peacocke's view, then, provides one way out of the alleged problem the regularity theorist faces. For Peacocke, we do indeed have experiences that represent our environment as causal, but - because one of the requirements for non-inferential perceptual knowledge is not met -such experiences cannot generate such knowledge. So the worry that the possibility of thick experience leads us, too cheaply, to knowledge of regularities - something we should not be able to know on the basis of just visual experience and philosophical theorising - is met. Thick experience does not, according to Peacocke, lead us there; on the contrary, the fact that knowledge of regularities is required in order for one to know that one's thick experiences are reliable precludes the possibility of non-inferential perceptual knowledge of causation.

3. Why Perceptual Knowledge of Causation doesn't Solve the Problem of Induction. I do not want to commit myself to a particular view about the necessary conditions for perceptual knowledge, and in particular I do not want to commit myself to the claim that perceptual knowledge is subject to internalist constraints. I therefore need to return to the original worry and argue that, even if such knowledge is possible, there are still no grounds for worrying that the regularity theorist has at her disposal a wildly implausible way of solving the problem of induction.

The worry is similar to the worry generated by a well-known argument which, it has been claimed, undermines semantic externalism. Roughly speaking, the problem arises from arguments like the following (W):

(W1) I am having a water thought

(W2) If I am having a water thought, then I live in a water world

Therefore

(W3) I live in a water world.

If I know (W1) by first person authority, and I know (W2) by conceptual analysis, it seems to follow that I can know (W3), an empirical proposition, without needing to conduct any empirical investigation whatever - which, some philosophers claim, is absurd.

The analogous argument $(\mathrm{P})$ in the case of knowledge of regularities runs as follows:

(P1) A caused B

(P2) If A caused B, then events like A are regularly associated with events like B.

Therefore

(P3) Events like A are regularly associated with events like B.

If I know (P1) by way of perceptual experience plus whatever else is needed for perceptual knowledge (no funny business, my perceptual mechanisms are in good working order, and so on), and I know (P2) by conceptual analysis, it seems to follow that I can know (P3), an empirical proposition about far-flung times and places, without needing to do any more than take a quick peek at the pool table - which, one might claim, is just as absurd. 
I have argued elsewhere (Beebee 2001) that (W) does indeed give us a way of knowing (W3), but that this result is not absurd because it does not provide a too-easy way of refuting scepticism: one cannot eliminate the possibility that one is a Twin-Earther just by reflecting on what one is thinking. The feature of (W) which blocks this possibility is the fact that it begs the question against the sceptic who accepts (W2) but who - being a sceptic - seriously doubts whether (W3) expresses a genuine thought, given the possibility that it might be content-defective. This is because someone who antecedently takes themselves to have reasons to doubt (W3) (in the above sense) will not take themselves to have warrant for (W1) and will not, therefore, be in a position to be persuaded by the argument.

The point about question-begging here is not that anyone who doubts (W3) but believes (W2) will (if they are rational) doubt (W1). Anyone who doubts the conclusion of a valid argument is rationally required to doubt at least one of the premises, so the question-begging nature of (W) does not simply rest on that. Instead, I appeal to Frank Jackson's account of begging the question, according to which an argument begs the question (against a given audience) if the audience's reasons for doubting the conclusion are also (by their lights) reasons to think that a particular premise is unwarranted.

Not all valid arguments beg the question in this sense. For example if you doubt that the Crows won the Grand Final on the grounds that they were up against a much better team, but you have not actually seen the Grand Final or heard the result of the game, I can persuade you that the Crows did in fact win by pointing out that The Australian reported that the Crows won and that The Australian never gets that kind of thing wrong. What is happening here, according to Jackson, is that in presenting the argument, I 'implicitly offer' evidence for the first premise, to the effect that I have seen the newspaper report. Since your initial grounds for doubting the conclusion do not give you grounds for doubting my ability to read newspaper reports accurately, you are in a position to 'borrow' that perceptual evidence and thereby come to have your doubts about the conclusion assuaged. In the case of an argument that begs the question, on the other hand, the hearer's reasons for doubting the conclusion are such that they will not take the evidence implicitly offered for one of the premises to be evidence (Jackson 1987: Chapter 6; Beebee 2001: 359-60). This is what makes (W) beg the question against the sceptic described above: her reasons for doubting (W3) are such that she is not in a position to think that first person authority provides a reason to believe (W1).

I shall argue that the same general strategy applies to $(\mathrm{P})$. Our question is whether, given the claim that perceptual knowledge of causation is possible, $(\mathrm{P})$ can be used to give us knowledge to the effect that an observed sequence of events instantiates a regularity. My answer is that it can (and indeed often does) - but that this does not give a too-easy way of resolving sceptical doubts about the continued orderliness of nature, since anyone who is plagued by such doubts will not take themselves to be in a position to run $(\mathrm{P}) ;(\mathrm{P})$, in other words, begs the question against the inductive sceptic.

The argument for this latter claim is quite straightforward. The rational inductive sceptic claims that we cannot know that the regularities we have observed in the universe thus far will continue to hold; and, being rational, she will take herself to have good reasons for this claim. Let us imagine an inductive sceptic who also takes herself to know (P2). Now, what position is our imagined sceptic in with respect to (P)? Well, she doubts (P3) but takes herself to know $(\mathrm{P} 2)$. She is therefore, of course, rationally required to doubt $(\mathrm{P} 1)$, since $(\mathrm{P})$ is manifestly a valid argument. But, as we saw above, that is not what makes the argument beg the question against her. What makes the argument beg the question is that her reasons for doubting (P3) are such that she is in no position to take her thick causal experiences to deliver knowledge of (P1). In particular, given her commitment to (P2), she is in no position to think 
that her causal experiences are at all reliable. Hence, while she may in fact know (P1) - if the conditions for perceptual knowledge are externalist conditions, and if she does indeed have thick causal experiences - she is in no position to believe that she knows. Hence she is in no position to run the argument and thereby assuage her sceptical doubts. ${ }^{10}$

What about someone who is merely neutral about whether or not $A$-type events are regularly associated with $B$-type events (perhaps because she has no experience of or background knowledge of such sequences)? Can she observe an $A-B$ sequence, note that she does in fact have a thick causal experience, and then run (P) and thereby come to know that $A$-type events are regularly associated with $B$-type events? Isn't that an absurd way to settle an inductive question? Well, there are plenty of circumstances in which we do, on the basis of a single experience, come to hold a general belief, and thereby take that belief to be reasonably held. You only need to stick your hand in the fire, or have someone's fist make contact with your nose, or have a particularly unpleasant injection once to feel justified in believing that it would be wise to avoid such events in the future if at all possible. And of course that belief is grounded in the belief that, if one doesn't avoid such events, the same unpleasant results will be likely to follow.

Is this a rational way of forming beliefs about what would happen in similar circumstances? I think so. How, then, are we to account for the reasonableness of the method? One might characterise it as a case of ordinary induction, of the 'some $A \mathrm{~s}$ are $B \mathrm{~s}$, so all (or most) $A$ s are $B \mathrm{~s}$ ' variety. But induction based on a single instance is not a very reliable method for forming general beliefs. We would do well to remember our Hume here: 'All reasonings concerning matters of fact seem to be founded on the relation of cause and effect' (1777: 26). A more plausible story than the straightforward inductive one is that we come to a causal belief (that we were burned by the fire, that the punch or the injection hurt us) and infer, on the basis of that belief, that if we find ourselves in the same circumstances again, the same unpleasant results will follow. If that is what we do, and we want to hold that future avoidance of contact with fires, fists or needles is rational, then we had better hold that it is rational to infer (P3) from (P1) in the case where one believes (P1) solely on the basis of one's causal experience. Indeed, we had better hold that this is rational whether or not we are regularity theorists.

Granting that we can have non-inferential perceptual knowledge of causation does not, I have argued, give us an implausibly easy response to the inductive sceptic. The inductive sceptic will not be in a position to run argument $(\mathrm{P})$ and thereby rationally persuade herself to renounce her scepticism, since she will not be in a position to take herself to know (P1) (even if in fact she does know it). However arguments like (P) do give the non-sceptic a way of knowing about regularities, but there is no harm in that. We often do form beliefs about regularities on the basis of a single observed case of causation, and I see no reason to regard this as irrational.

\section{IV}

Conclusion. I have argued that, insofar as there are independent reasons to think that thick causal experiences are possible, nothing stands in the way of a regularity theorist accepting that claim. This is not to say that everything in the regularity theorist's garden is rosy, however. The traditional motivation for regularity theories is Hume's claim that 'all events

\footnotetext{
${ }^{10}$ Schlottmann reports that she 'rarely see[s] ... causality any more, having learned to analyze the events into their spatio-temporal constituents' (2000: 441). Perhaps inductive sceptics are in the same position - in which case they certainly cannot non-inferentially perceptually know (P1).
} 
seem entirely loose and separate. One event follows another; but we never can observe any tie between them' (Hume 1777: 74). ${ }^{11}$ It has been pointed out by singularists that this claim, if true, should not lead us to conclude that there are no intrinsic causal relations (Menzies 1998), and even that it did not lead Hume to that conclusion (Strawson 1989). It has also been claimed by singularists that it is not even true that 'all events seem entirely loose and separate', and thus that Hume's (alleged) argument for the extrinsicality of causation fails for that reason (Anscombe 1993, Menzies 1998). I agree with both criticisms, and thereby acknowledge that any argument from the impossibility of causal experience to the extrinsicality of causation is bound to fail. This leaves the regularity theorist with a serious piece of unfinished business: the business of providing alternative positive reasons to believe that causation is not an intrinsic relation. ${ }^{12}$

Centre for Philosophy, Department of Government

University of Manchester

Oxford Road, Manchester M13 9PL

helen.beebee@man.ac.uk

\section{REFERENCES}

Anscombe, G.E.M., 1993, 'Causality and Determination', reprinted in Causation, ed. E. Sosa and M. Tooley (Oxford: Oxford University Press).

Armstrong, D.M., 1993, 'Reply to Menzies', in Bacon, Campbell and Reinhardt 1993.

Armstrong, D.M., 1997, A World of States of Affairs, Cambridge: Cambridge University Press.

Beebee, H., 2001, 'Transfer of Warrant, Begging the Question and Semantic Externalism', Philosophical Quarterly 51: 356-74.

Blackburn, S., 1984, Spreading the Word, Oxford: Oxford University Press.

Cartwright, N., 2000, 'An Empiricist Defence of Singular Causes', in Logic, Cause and Action, ed. R. Teichmann, Cambridge: Cambridge University Press.

Ducasse, C.J., 1967a, 'Causation: Perceivable? Or only inferred?', Philosophy and Phenomenological Research 26: 173-9.

Ducasse, C.J., 1967b, 'How literally causation is perceivable', Philosophy and Phenomenological Research 28: 271-3.

11. Actually, so far as I can tell Hume only ever makes this kind of claim in the context of the experience of successions of events, similar conjunctions of which we have not previously experienced. This leaves open the possibility that, even for Hume, we can experience events as causal given the kind of habituation that generates the 'impression of necessary connexion'. This, I take it, is Simon Blackburn's suggestion when, in the context of stressing Hume's projectivism about causation, he complains that we fail to engage with Hume if we 'merely insist, as many thinkers do, that we properly describe the perceived states of affairs in causal terms - see bricks splashing in water, balls breaking windows, things pushing and pulling. Certainly we do: but what is the best explanation of our so seeing them?' (1984: 211-2)

12. Many thanks to Alexander Bird, Julian Dodd, Mike Martin, Paul Noordhof, Stathis Psillos, Michael Rush, and Michael Scott for very helpful comments and suggestions, not all of which I have addressed adequately. Thanks also to the audience at the Metaphysics of Science workshop in Edinburgh in December 2002, and to audiences at Macquarie, Manchester, Leeds, and the BSPS who, a long time ago, heard and commented on a distant ancestor of this paper. 
Ducasse, C.J., 1993, 'On the Nature and Observability of the Causal Relation', reprinted in Causation, ed. E. Sosa and M. Tooley (Oxford: Oxford University Press).

Ehring, D., 1997, Causation and Persistence, New York: Oxford University Press.

Fales, E, 1990, Causation and Universals, London and New York: Routledge.

Fodor, J., 1983, 'Observation Reconsidered', Philosophy of Science 51: 23-43.

Goldman, A.I., 1976, 'Discrimination and Perceptual Knowledge', Journal of Philosophy 73: 771-91.

Heathcote, A. and D.M. Armstrong, 1991, 'Causes and Laws', Nous 25: 63-73.

Hume, D., 1777, Enquiries Concerning Human Understanding and Concerning the Principles of Morals, $3^{\text {rd }}$ edition ed. L.A. Selby-Bigge and P.H. Nidditch, Oxford: Clarendon Press 1978.

Jackson, F., 1987, Conditionals (Oxford: Blackwell).

Leslie, A. and S. Keeble, 1987, 'Do Six-Month-Old Infants Perceive Causality?', Cognition 25: $265-88$.

Menzies, P., 1998, 'How Justified are the Humean Doubts about Intrinsic Causal Links?', Communication \& Cognition 31: 339-64

Michotte, A., 1963, The Perception of Causality (London: Methuen).

Nozick, R., 1988, 'Knowledge and Scepticism', in Perceptual Knowledge, ed. J. Dancy (Oxford: Oxford University Press).

Peacocke, C., 1986, Thoughts: An Essay on Content (Oxford: Blackwell).

Schlottmann, A., 2000, 'Is Perception of Causality Modular?', Trends in Cognitive Sciences 4: 441-2.

Schlottmann, A. \& D. Shanks, 1992, 'Evidence for a Distinction between Judged and Perceived Causality', Quarterly Journal of Experimental Psychology 44: 321-42

Scholl, B.J. \& P.D. Tremoulet, 2000, 'Perceptual Causality and Animacy', Trends in Cognitive Sciences 4: 299-309.

Spelke, E.S. \& G.A. Van de Valle, 1993, 'Perceiving and Reasoning about Objects: Insights from Infants' in Spatial Representation, ed. N. Eilan, R. McCarthy and B. Brewer (Oxford: Oxford University Press).

Strawson, G., 1987, 'Realism and Causation', Philosophical Quarterly 37: 253-77.

Strawson, G., 1989, The Secret Connexion, Oxford: Oxford University Press. 